\title{
KAOLIN BENEFICIATION IN A HIGH-GRADIENT MAGNETIC SEPARATOR WITH A BALL MATRIX
}

\author{
E.A. SULTANOVICH ${ }^{\star}$ AND V.I. KARMAZIN $^{\dagger}$ \\ ${ }^{\star}$ Technion, Haifa 32000, Israel \\ $\dagger$ Mining Institute, Dnepropetrovsk, Ukraine
}

(Received February 12, 1993, revised May 17, 1993)

\begin{abstract}
Results are given of investigations into the determination of the main structural and technological parameters of a high-gradient magnetic separator with a ball matrix. The design has been developed and a possibility has been outlined of effective beneficiation of kaolin at the magnetic induction 1.0 to $1.2 \mathrm{~T}$. Comparative tests of separators with a ball matrix and a steel wool matrix (SALA-HGMS) have shown that the parameters of separation are the same. In the former case, however, a considerable reduction in specific input of metal, electrical energy, water and air per tonne of product is achieved. The advantage of the ball matrix is most fully displayed at the extraction of finely dispersed weakly magnetic particles from ores and slimes of low content of magnetic fraction.
\end{abstract}

\section{INTRODUCTION}

The deterioration of quality of raw materials has resulted in reduced output of better grades of kaolin which are inconsiderable demand in the porcelain and paper industries and elsewhere. The removal of weakly magnetic minerals from kaolin clay is the decisive factor in their processing. The most severe difficulties are encountered in the removal of fine particles of ferrotitanium compounds, several micrometers in size, and linked with silicate lattice. In order to solve this problem, 
high-gradient magnetic separation (HGMS) has found a wide application and is now competing with traditional beneficiation processes.

In magnetic beneficiation of kaolin, an important aspect is finding a matrix that permits effective extraction of weakly magnetic finely dispersed particles, and the optimum regime parameters for the separation process [1 to 3]. Over the last years, steel wool has been widely used as a matrix [3,4]. Such a wool consists of thin wires 20 to $50 \mu \mathrm{m}$ in diameter and it permits effective extraction of finely dispersed 1 to $2 \mu \mathrm{m}$ particles. Such a design suffers, however, from the drawback of increased energy consumption, excessive metal input and difficulties with matrix regeneration, and an urgent solution is needed.

This paper presents the results of investigations into a design based on a ball matrix., as compared to SALA separators. The experiments were conducted at kaolin plants in the Ukraine (Prosyanaya and Glukhovtsy), the largest in Europe.

\section{DESIGN AND OPERATION PRINCIPLES OF EXPERIMENTAL}

\section{BALL-MATRIX SEPARATOR}

The design, shown in Figure 1, was developed at the State Design Institute for Processing Equipment in Lugansk, Ukraine. The separator, operating in a cyclic mode, under automatic control, consists of an electromagnetic system 1 and bath 2 , mounted in the gap of the electromagnet. The bath contains a cassette 3 filled with ferromagnetic balls. The electromagnetic coils are cooled by the fans. The separator is equipped with a centrifugal cleaning system for the layer of balls and for the discharge of the magnetic fraction.

The feed material is uniformly distributed throughout the canister with the aid of unit 4, and the products of beneficiation are discharged through the outlet 5 , whose diameter determines the output of the separator.

The operational principle of the separator consists in the following. With the electromagnetic system switched on, the high-intensity magnetic field is induced in the ball layer. A suspension containing up to $30 \%$ of solids is introduced into the working region and filtered through the balls. Non-magnetic particles pass, 
together with the water, and are discharged into a compartment for cleaned material; the magnetic particles are trapped by the balls.

On completion of the cleaning process the field is switched off, the ball are regenerated and the magnetic product is discharged. The cycle of the separator is the sum of the times of the cleaning as well as regeneration and discharge stages. Preparatory operations associated with the cycle include the interruption of the feed and the switching on and off of the electromagnetic system, all of them performed automatically via a program prescribed by the control station.

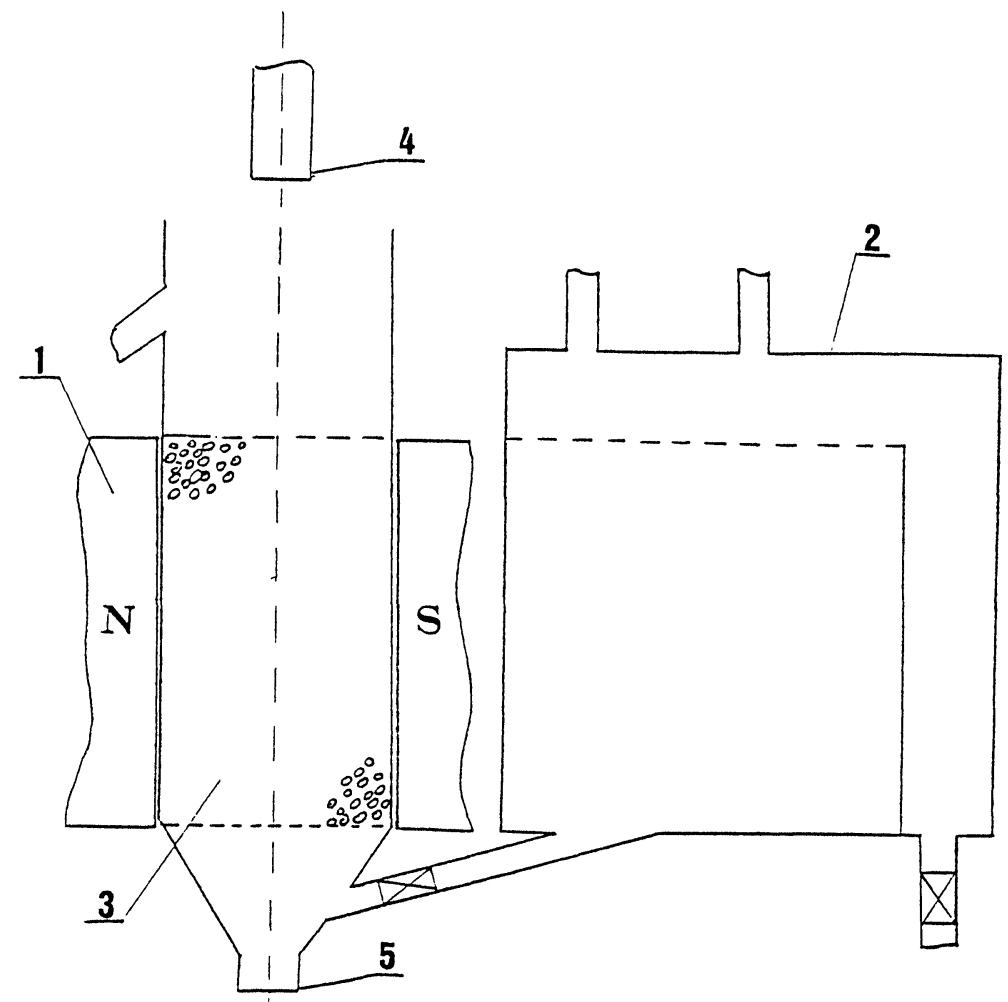

FIGURE 1 Schematic diagram of the experimental ball matrix magnetic separator

On the basis of the above described model, the main structural and technological parameters were determined for industrial ball matrix separators for kaolin 
beneficiation, with output - 2 to 8 tonnes per hour. These parameters are summarised in Table I.

TABLE I Parameters of the separator

Dimensions of the working region

Throughput

Magnetic induction in the ball layer

with the cooling of the coils without cooling

Feed size

Feed supply to the working region

Pressure of compressed air

Ferromagnetic matrix

Dimensions of the plant

length

width

height

Mass
$57 \times 57 \times 200 \mathrm{~mm}$

$60 \ell / \mathrm{h}$

$2.0 \mathrm{~T}$

$1.85 \mathrm{~T}$

$-0.1 \mathrm{~mm}$

top

less than $0.25 \mathrm{~atm}$

Balls 2 to $4 \mathrm{~mm}$ in diameter

$1580 \mathrm{~mm}$

$1250 \mathrm{~mm}$

$1840 \mathrm{~mm}$

$3900 \mathrm{~kg}$

\section{INDUCTION OF THE MAGNETIC FIELD}

The generation of strong magnetic fields with intensity $2 \mathrm{~T}$ and higher entails great difficulties and considerable energy consumption (the power of an electromagnet varies as the field intensity squared). At present, an increase in the field gradient is mostly effected using steel filaments up to $200 \mu \mathrm{m}$ or more in diameter. With this technique, the recovery of weakly magnetic particles smaller than 1 to $2 \mu \mathrm{m}$ is incomplete and the matrix of small steel balls is more effective.

The magnetic field in high-gradient ball separators occupies the entire space of the working region and contains multiple spatial gradients which intensify the magnetostatic component of the magnetic energy in the gap [5, 6]. This allows to 
generate strong magnetic forces uniformly distributed throughout the gap, and thereby complete recovery of fine weakly magnetic fractions.

Magnetic induction in a layer of balls is governed by the effective permeability of the layer of the balls, which in turn depends not only on the material of the balls but also on their arrangement, on the level of the recovery of the magnetic fraction etc. The magnetic induction reaches the saturation level of the material of the balls in the vicinity of the points of contact of the balls. The saturation zone is extended as the excitation intensity increases. At the ratio of 3 between the distance of a chosen point to that of the contact, and the ball radius, this extension is very small [5]. In practice there exists a limit of the excitation intensity, beyond which the recovery no longer increases.

Figure 2 shows the dependence of the magnetic induction versus electric current, for balls of 2 to $3 \mathrm{~mm}$ in diameter. Beyond the $20 \mathrm{~A}$ current level the magnetic induction increases less steeply with the increasing current. For instance, if the magnetic induction is $1.35 \mathrm{~T}$ at $30 \mathrm{~A}$, then at $35 \mathrm{~A}$ it increases by $0.03 \mathrm{~T}$ only, while the respective increment when the current changes from 10 to $15 \mathrm{~A}$ is $0.2 \mathrm{~T}$. In kaolin beneficiation, the optimum recovery of the weakly magnetic oxides of iron and titanium corresponds to the induction level of 1.0 to $1.2 \mathrm{~T}$, above which there is a drop in the efficiency (Figure 3).

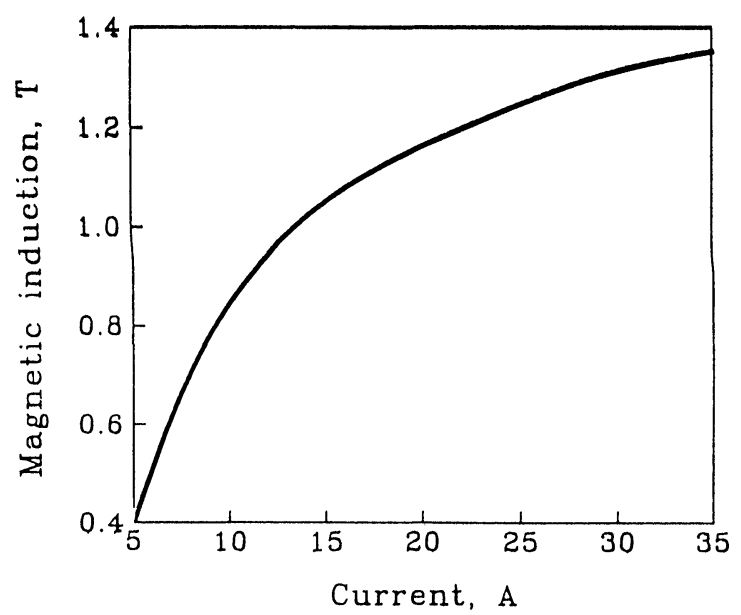

FIGURE 2 The dependence of magnetic induction on electrical current (ball diameter 2 to $3 \mathrm{~mm}$ ) 


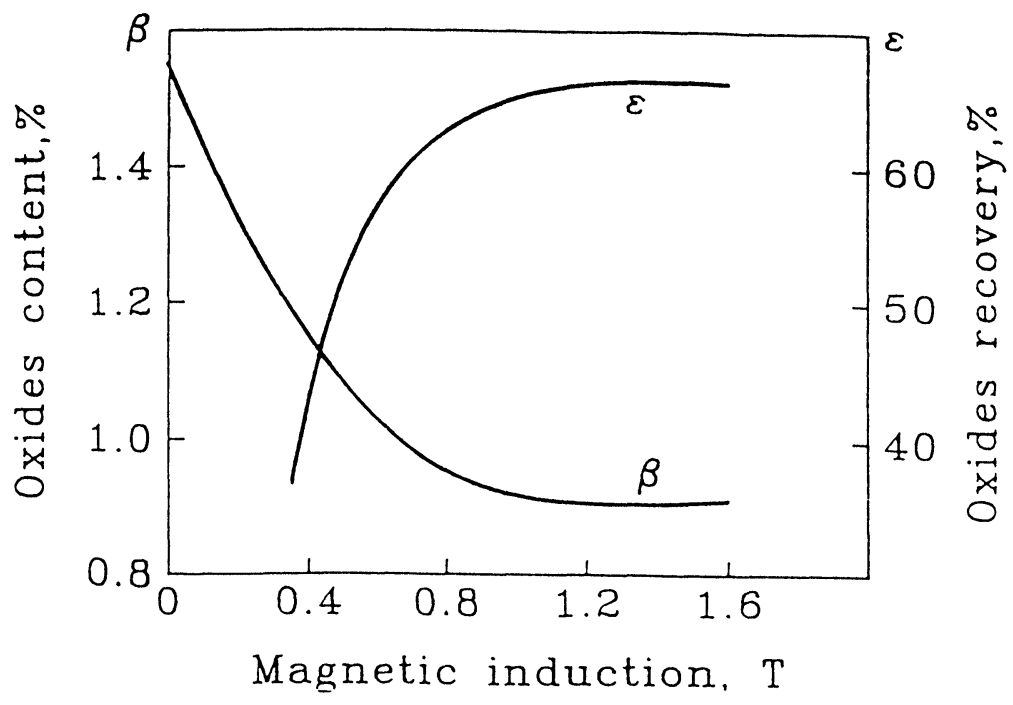

FIGURE 3 The influence of magnetic induction on the parameters of beneficiation of kaolin.

$\beta-\mathrm{Fe}_{2} \mathrm{O}_{3}$ and $\mathrm{TiO}_{2}$ content in the concentrate (\%)

$\epsilon$ - the recovery of $\mathrm{Fe}_{2} \mathrm{O}_{3}$ and $\mathrm{TiO}_{2}$ into the tails (\%)

\section{SIZE OF SPHERICAL MATRIX ELEMENTS}

The mean magnetic force acting on a particle in a plane perpendicular to the magnetic flux at a distance $x$ (as a fraction of the radius) from the centre of a ball is given [5] by:

$$
\mathrm{H} \frac{\mathrm{dH}}{\mathrm{dx}}=\frac{3.868 \mathrm{M}_{b}^{2}(\mathrm{~K}+0.274)(\mathrm{K}-1)^{2}}{\ell^{2} \mathrm{r} \mathrm{K}_{1}^{2}}
$$

where $\mathrm{M}_{\mathrm{b}}$ is the magnetomotive force (in $A$ ), $r$ is the radius of a ball (in $m$ ), $\ell$ is the length of the working region (in $m$ ). The parameters $K$ and $K_{1}$ are given by:

$$
\mathrm{K}=\frac{\mu_{1}}{\mu_{2}} \quad \mathrm{~K}_{1}=\ln \frac{(\mathrm{K}+0.274)^{\frac{1}{2}}+(\mathrm{K}+1)^{\frac{1}{2}}}{(\mathrm{~K}+0.274)^{\frac{1}{2}}+(\mathrm{K}-1)^{\frac{1}{2}}}
$$


where $\mu_{1}$ and $\mu_{2}$ are the magnetic permeabilities of the ball material and of the medium (in this case the ore), respectively.

The maximum value of the force is observed when $x$ approaches $r$. It follows from the above that the forces of a multigradient field generated by spherical magnetizable bodies increase with decreasing radius of the ball, and with increasing ratio of permeabilities of the ball material and the medium. For this reason, small weakly magnetic particles are recovered from a suspension with the aid of small balls made of a soft steel with $M$ increased and the gap between the magnetizing poles narrowed.

Figure 4 shows the dependence of the concentration of oxides and of their recovery on the ball diameter. It can be seen that the optimum diameter is 2 to $3 \mathrm{~mm}$.

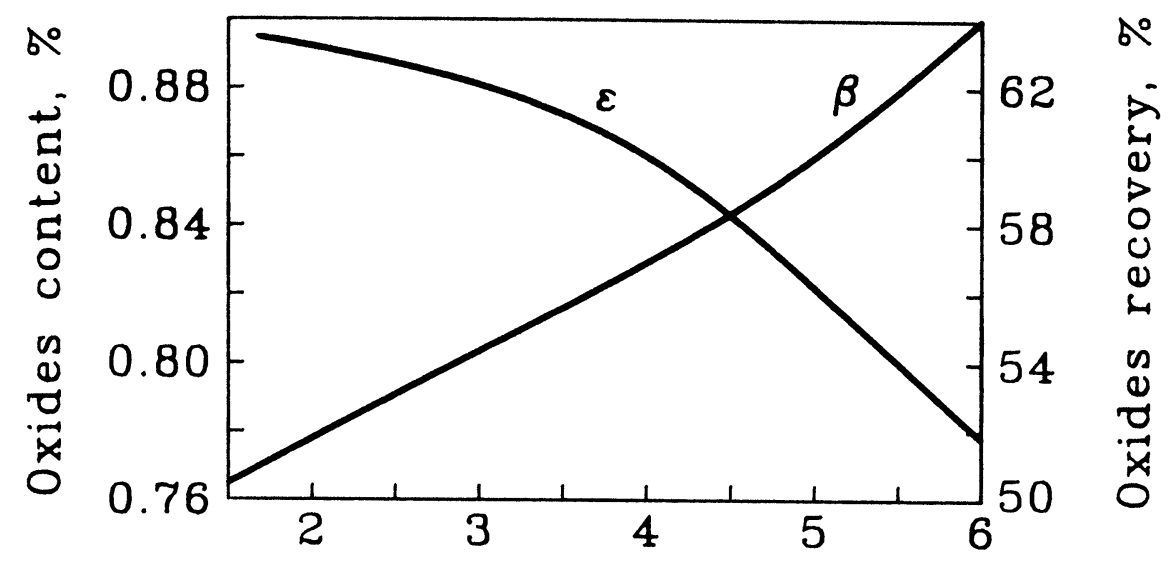

\section{Ball diameter, $\mathrm{mm}$}

FIGURE 4 The influence of the ball diameter on the concentration $(\beta)$ of oxides $\left(\mathrm{Fe}_{2} \mathrm{O}_{3}+\mathrm{TiO}_{2}\right)$ in the concentrate, and on the recovery $(\epsilon)$ of the oxides into the tailings. Magnetic induction $1.0 \mathrm{~T}$.

\section{LENGTH OF THE SEPARATION ZONE}

The thickness of the layer of the balls in the working zone of a separator has a considerable influence on the qualitative and quantitative indices of the 
beneficiation process. The concentration of the discolouring oxides $\mathrm{Fe}_{2} \mathrm{O}_{3}$ and $\mathrm{TiO}_{2}$ in kaolin being very small, their magnetic permeability low and the material fine, an extended residence time (30 to $120 \mathrm{sec}$ ) in the magnetic field is necessary, in addition to high gradient. This is obtainable by lengthening the separation region and by reducing the rate of filtration. Figure 5 shows the dependence of the concentration of the magnetic oxides in kaolin on the length of the separation zone, whose influence is substantial.

For instance, while the layer of the ball $150 \mathrm{~mm}$ deep, at the magnetic induction of $1.0 \mathrm{~T}$ the concentration of the oxides drops from $1.26 \%$ to $1.06 \%$, the concentration decreases to $0.75 \%$, with the layer of balls $300 \mathrm{~mm}$ deep, at the same magnetic induction. This is characteristic of lower induction levels as well. In the second pass, the concentration of oxides further decreases by 0.1 to $0.15 \%$, confirming the usefulness of an extended working zone.

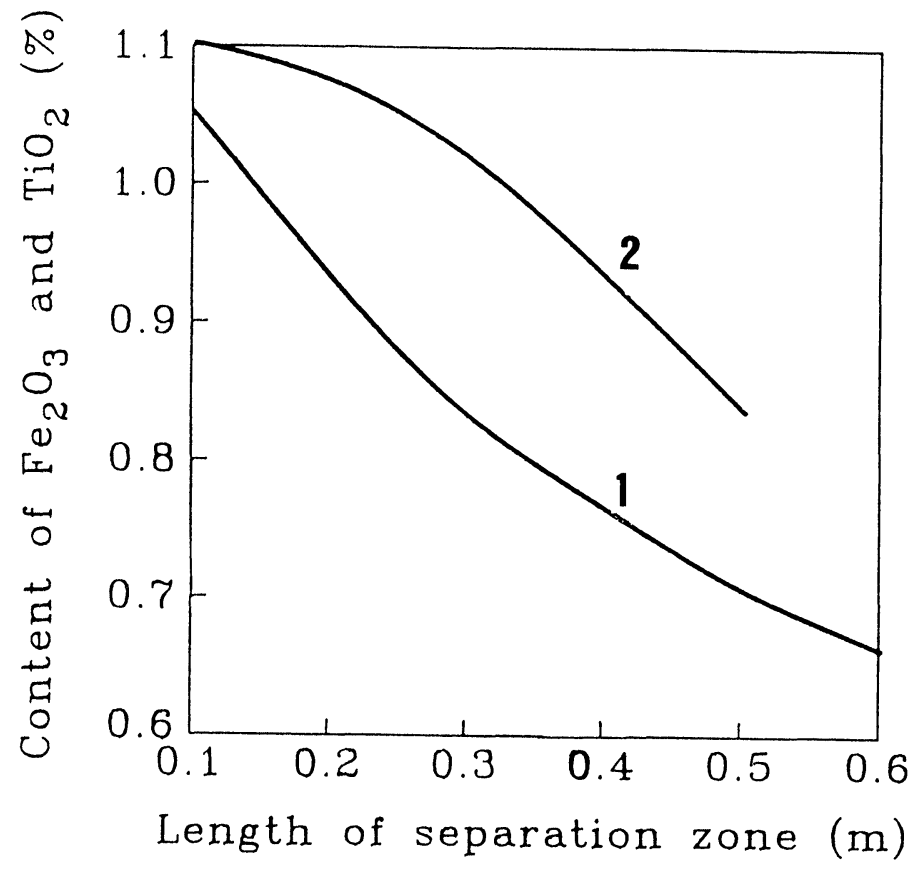

FIGURE 5 The influence of the length of the separation zone on the concentration of the oxides (ball diameter 2 to $3 \mathrm{~mm}$ ).

1 - magnetic induction $1.0 \mathrm{~T}$

2 - magnetic induction $0.4 \mathrm{~T}$. 


\section{THE FILTRATION RATE AND THROUGHPUT}

The physical regime in multigradient separation is determined mainly by the magnetic and hydromechanical forces in the working region whose role in paramount for fine material. A kaolin suspension containing containing up to $25 \%$ solids should flow through the ball layer in a near-laminar mode. This is feasible with small-sized matrix elements and at low flowrates. At large values of these parameters the suspension moves in a mixed turbulent-laminar mode, with the shape of each element governed by the velocity of the suspension and by its viscosity.

An increase in the turbulence element gives rise to hydromechanical forces exceeding the magnetic force, thereby sharply reducing the likelihood of trapping the weakly magnetic particles. Figures 6 and 7 show the influence of the filtration rate of the material through a layer of balls 2 to $3 \mathrm{~mm}$ in diameter on the throughput and on the recovery of the oxides. At the filtration rate of 5 to $6 \mathrm{~mm} / \mathrm{s}$ the specific throughput of the separator is $2 \mathrm{t} / \mathrm{h} / \mathrm{m}^{2}$ and the recovery level is $70 \%$.

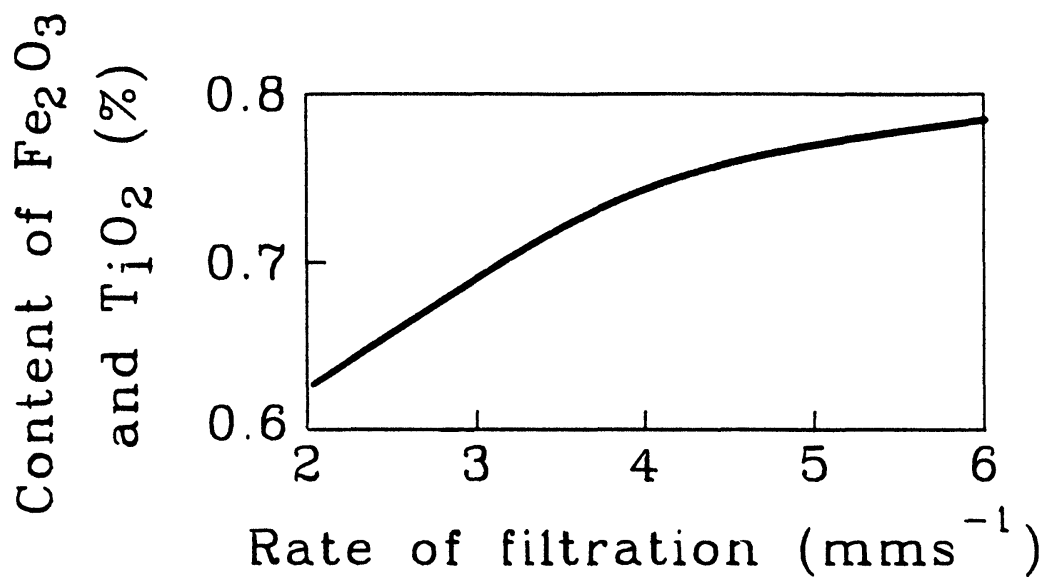

FIGURE 6 The dependence of the concentration of the oxides on the rate of filtration (ball diameter 2 to $3 \mathrm{~mm}$, magnetic induction $1.0 \mathrm{~T})$ 


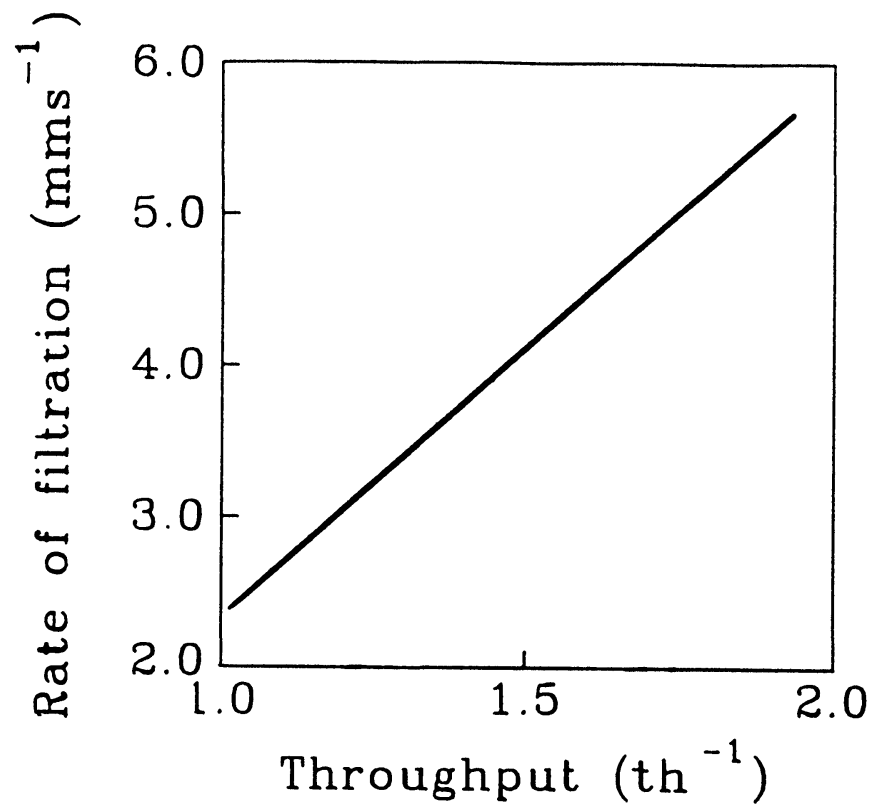

FIGURE 7 The dependence of the throughput on the rate of filtration (ball diameter 2 to $3 \mathrm{~mm}$, magnetic induction $1.0 \mathrm{~T}$ )

\section{INDUSTRIAL EXPERIMENTS}

An industrial separator with the ball matrix (Figure 8) was developed on the basis of laboratory investigations and was installed in parallel with the SALA-HGMS 107-30-20-250 unit at a kaolin processing plant.

Figure 9 shows the layout of a pilot-plant circuit developed by the Institute of Non-metallic Materials, Togliatti, Russia. THe mining of raw kaolin, its breaking up, separation of coarse sands and hydrocycloning are effected by the technology adopted at the plant. From the hydrocyclones (150 mm in diameter) the kaolin suspension is delivered to a vibrosieve 1 with a cell size $0.063 \mathrm{~mm}$. The screened product from tank 2 is transferred by a pump to a contact tank 3 into which a dispersing agent (sodium meta- or poly-phosphate) is also added. 
From the collecting tank 4 the suspension is transferred by a pump into electromagnetic separators 5 . The magnetic fraction from the separator is discharged into sewage 6 . The non-magnetic product, to which a lime solution is added in the case of low density, is dehydrated in chamber filter presses 7 , then passed through a drier 8 and transported to the finished product area 9.

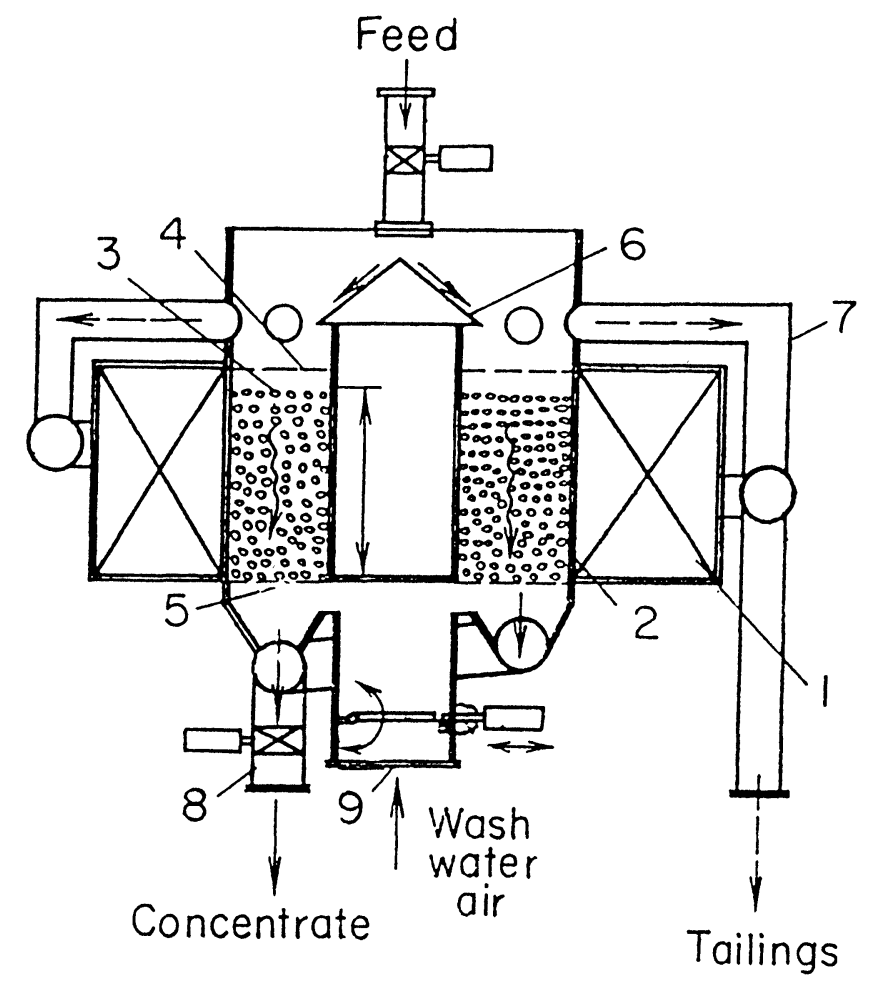

FIGURE 8 Schematic diagram of the magnetic separator with the ball matrix

In the preliminary investigation and in the industrial tests, the optimum density of the feed, the throughput of the separator, the performance of principal units and of the automation system, the efficiency of the re-cleaning operation, the cyclicity of the set-up and the recovery of the iron and titanium oxides, versus their concentration in the feed were also determined. The most important techno-economic data on the separators that were compared in our study are summarized in Table II. 
TABLE II Techno-economic data of the separators

\begin{tabular}{|c|c|c|}
\hline & SALA-HGMS & SDIPE $^{\star}$ \\
\hline Type of electromagnetic system & coil & coil \\
\hline Matrix & steel wool & balls \\
\hline Cooling technique & water & water \\
\hline Filtration area, $\mathrm{m}^{2}$ & 1.07 & 1.0 \\
\hline Size of matrix element, $\mathrm{mm}$ & $0.03-0.05$ & $2.0-3.0$ \\
\hline Depth of matrix, mm & 300 & 450 \\
\hline Magnetic induction in matrix, $\mathrm{T}$ & 1.9 & 1.0 \\
\hline Throughput of solids, $t / h$ & 2.0 & 2.0 \\
\hline $\begin{array}{l}\text { Total concentration of } \\
\text { Fe \& Ti oxides, } \% \\
\text { in the feed } \\
\text { in the non-mag. product } \\
\text { in the magnetic fraction }\end{array}$ & $\begin{array}{l}1.47-1.56 \\
0.87-0.93 \\
2.1-2.3\end{array}$ & $\begin{array}{l}1.47-1.56 \\
0.88-0.92 \\
2.2-2.5\end{array}$ \\
\hline Field excitation power, $\mathrm{kW}$ & 250 & 72 \\
\hline Mass of magnetic system, $\mathrm{t}$ & 46 & 11 \\
\hline Total mass, $\mathrm{t}$ & 52 & 18.3 \\
\hline $\begin{array}{l}\text { Specific mass of separator } \\
\text { per feedrate, } t . h / t\end{array}$ & 26 & 9 \\
\hline $\begin{array}{l}\text { Specific consumption: } \\
\text { Electric energy, } \mathrm{kWh} / \mathrm{t}\end{array}$ & 125 & 37.5 \\
\hline Industrial water, $\mathrm{m}^{3} / \mathrm{t}$ & 40 & 4 \\
\hline $\begin{array}{l}\text { Air, } \mathrm{m}^{3} / \mathrm{t} \\
\text { Dispersing agent, } \mathrm{kg} / \mathrm{t}\end{array}$ & $\begin{array}{l}40 \\
3.6\end{array}$ & $\begin{array}{l}2.5 \\
3.6\end{array}$ \\
\hline
\end{tabular}

${ }^{\star}$ The State Design Institute for Processing Equipment, Ukraine 


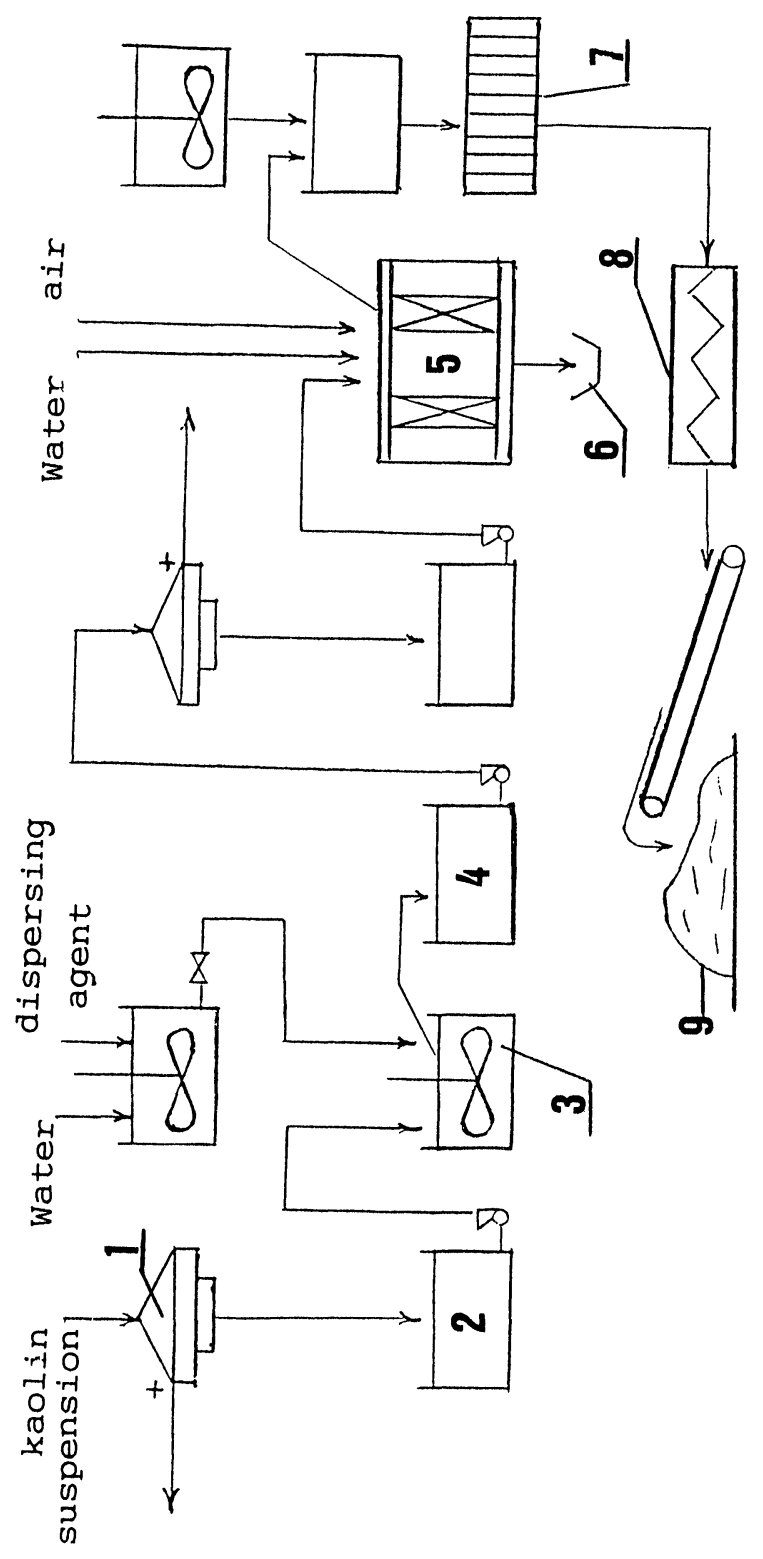

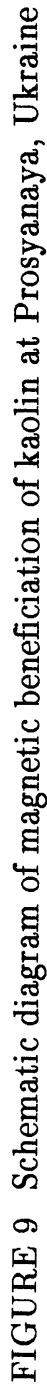




\section{CONCLUSION}

A high-gradient magnetic separator with the ball matrix, for the recovery of fine weakly magnetic oxides from kaolin was developed and tested. The use of small balls as a matrix, in conjunction with corresponding parameters ( magnetic induction of $1 \mathrm{~T}$, the length of the separation zone of 400 to $500 \mathrm{~mm}$, the filtration rate of suspension of $5 \mathrm{~mm} / \mathrm{s}$ through the matrix) resulted in a high-quality product. The concentration of iron oxide in the kaolin decreased, on average, from $0.51 \%$ to $0.27 \%$, and of titanium oxide from $1.05 \%$ to $0.65 \%$, with a considerable decrease in the sieve tailings $(0.063 \mathrm{~mm})$. The brightness of the kaolin improved by 3 to $4 \%$, and reached 82 to $83 \%$.

The use of the ball matrix, instead of steel wool, reduced the metal input of the system by a factor of 2.5 , the consumption of electric energy by a factor of 3 , and the consumption of water and air for the regeneration of the matrix by a factor of 10 or more.

The reliability of the setup and of the regeneration system was established. The superiority of the ball matrix was best demonstrated by the recovery of fine weakly magnetic particles from ores and slimes with low content of the magnetic fraction.

\section{ACKNOWLEDGMENT}

The authors wish to thank Professor I.J. Lin for his attention to this work and for valuable discussions and helpful comments.

\section{REFERENCES}

1. V.I. Karmazin et al.: Reduction of coloured oxides in kaolin by magnetic separation in strong fields. Akademiya Nauk SSSR, Kolsk. Fil., Apatity, USSR (1985), p. 71 (in Russian) 
E.A. Sultanovich et al.: Removal of iron and titanium oxides from kaolin by magnetic separation in strong fields. Dressing of Minerals, Moscow, Nauka (1987), (in Russian)

V. Hencl: Mag. Electr. Sep. 3 (1991), 33

4. J. Svoboda: Magnetic Methods for the Treatment of Minerals, Elsevier, Amsterdam (1987)

5. V.I. Karmazin and V.V. Karmazin: Magnetic Methods of Beneficiation. Nedra, Moscow (1987), (in Russian)

6. V.V. Karmazin and V.I. Karmazin: Magnetic and Electrical Methods of Beneficiation. Nedra, Moscow (1988), (in Russian)

E. Sultanovich , D.Sc. has am extensive experience at the world's largest mining and beneficiation plants (Krivoy Rog, Ukraine). Since 1963 he was involved as a researcher and head of a research group in the development of effective methods of magnetic beneficiation of ores and minerals, of coal desulphurization and of extraction of weakly magnetic inclusions from suspensions. Dr. Sultanovich is the author of 83 publications and of 11 inventions. Presently he holds a position of a researcher at the Department of Mineral Engineering, Technion, Haifa, Israel.

V.I. Karmazin: for biography, see Mag.Electr. Sep. 3 (1992), 77

Keywords magnetic separation, high-intensity magnetic separator, ball matrix, kaolin, oxides 